\title{
Divulgação científica na escola: apresentando as libélulas (Odonata: Insecta) através de um projeto de extensão
}

As atividades de extensão são importantes para a troca de conhecimento científico e popular, realizadas com o intuito de aproximar o meio acadêmico e a sociedade, possibilitando o desenvolvimento de ações para a popularização da ciência e da divulgação científica. Desta forma, objetivamos difundir o conhecimento sobre os insetos aquáticos, com foco nas libélulas, e a importância da preservação dos igarapés e das comunidades biológicas através da popularização da ciência. $\mathrm{O}$ trabalho foi desenvolvido como ação de um projeto de extensão realizado em uma escola pública tendo como participantes educandos dos 20 e 30 anos do ensino médio no município de Altamira (PA). Foram realizadas palestras e exposição de jogos didáticos utilizando os temas "meio ambiente" e "libélulas" com o intuito de levar o conhecimento à escola de forma lúdica, além de um questionário diagnóstico para avaliar quais nomes populares das libélulas e quais personagens em filmes ou desenhos com libélulas os alunos conheciam. Através da atividade foi possível observar que alguns alunos apresentavam conhecimentos prévios sobre as libélulas, porém não sabiam que estas, na sua fase larval se desenvolvem no ambiente aquático e qual sua importância ecológica, reforçando a relevância de projetos de extensão voltados para divulgação cientifica do grupo como ferramenta para educação ambiental.

\section{Scientific dissemination in school: presenting the dragonfly (Odonata: Insecta) through an extension project}

\begin{abstract}
Extension activities are important for the exchange of scientific and popular knowledge, carried out with the aim of bringing the academic environment and society closer together, enabling the development of actions for the popularization of science and scientific dissemination. In this way, we aim to spread knowledge about aquatic insects, with a focus on dragonflies, and the importance of preserving streams and biological communities through the popularization of science. The work was developed as an action of an extension project carried out in a public school with the participation of students from the 2 nd and 3 rd years of high school in the municipality of Altamira (PA). Lectures and didactic games were presented using the themes "environment" and "dragonflies" in order to take knowledge to school in a playful way, in addition to a diagnostic questionnaire to assess which popular names of dragonflies and which characters in films or drawings with dragonflies the students knew. Through the activity it was possible to observe that some students had previous knowledge about dragonflies, but they did not know that they, in their larval phase, develop in the aquatic environment and what their ecological importance is, reinforcing the relevance of extension projects aimed at scientific dissemination of the group as a tool for environmental education.
\end{abstract}

Keywords: Aquatic insects; Dragonflies; Environmental education; Ludic; Popularization of science.

Topic: Ensino Superior, Pesquisa e Extensão

Reviewed anonymously in the process of blind peer.
Received: 02/03/2021

Approved: 24/05/2021
Kesley Gadelha Ferreira (iD

Universidade Federal do Pará, Brasil

http://lattes.cnpq.br/4224277543586339

http://orcid.org/0000-0003-0315-1106

keslevgadelha@gmail.com

José Max Barbosa de Oliveira Junior

Universidade Federal do Oeste do Pará, Brasi

http://lattes.cnpq.br/1353014365045558

http://orcid.org/0000-0002-0689-205X

josemaxoliveira@gmail.com

Kenned da Silva Sousa (i)

Universidade Federal do Pará, Brasil

http://lattes.cnpq.br/2837725827503533

http://orcid.org/0000-0001-8959-7525

kenned272@gmail.com

\author{
Paulo Augusto Feitosa de Oliveira (1D \\ Universidade Federal do Pará, Brasil \\ http://lattes.cnpq.br/6671121577746666 \\ http://orcid.org/0000-0002-7332-8918 \\ pauloaugustolm@gmail.com \\ Ronaldo Adriano Ribeiro da Silva (it \\ Universidade Federal do Pará, Brasil \\ http://lattes.cnpq.br/2020211060475648 \\ http://orcid.org/0000-0002-4974-4620 \\ ronaldobiologiaufpa@gmail.com \\ Karina Dias Silva (iD \\ Universidade Federal do Pará, Brasil \\ http://lattes.cnpq.br/2271768102150398 \\ http://orcid.org/0000-0001-5548-4995 \\ diassilvakarina@gmail.com
}

Referencing this:

FERREIRA, K. G.; OLIVEIRA JUNIOR, J. M. B.; SOUSA, K. S.; OLIVEIRA, P. A. F.; SILVA, R. A. R.; SILVA, K. D.. Divulgação científica na escola: apresentando as libélulas (Odonata: Insecta) através de um projeto de extensão. Nature and Conservation, v.14, n.2, p.204-212, 2021. DOI: http://doi.org/10.6008/CBPC2318-2881.2021.002.0018 


\section{INTRODUÇÃO}

Os ecossistemas aquáticos estão sob intensa pressão antrópica tais como conversões da vegetação ripária para monoculturas, urbanização, criação de gado e mineração (ALLAN, 2004; COUCEIRO et al., 2007; JUEN et al., 2017). Estes impactos tem levado ao empobrecimento da qualidade dos corpos d'água e tendo como consequência a perda de diversidade dos organismos aquáticos que habitam e dependem destes ambientes (DALA-CORTE et al., 2020), assim buscar formas de popularizar o conhecimento através de uma linguagem acessível e compreensível para sensibilizar a comunidade sobre temas voltados para a preservação do ambiente tem sido a meta dos pesquisadores, visto que é necessário que a população seja incentivada ao interesse pela ciência (BRIED et al., 2020; MATEUS et al., 2017).

De acordo com Bueno (1988) a divulgação científica compreende a "[...] utilização de recursos, técnicas, processos e produtos (veículos ou canais) para a veiculação de informações científicas, tecnológicas ou associadas a inovações ao público leigo". Dessa forma cabe aos divulgadores científicos realizar uma transposição didática acerca das informações possibilitando a compreensão e o entendimento com o uso de recursos visuais e materiais, metodologias e técnicas adequadas e adaptadas ao público.

A popularização da ciência possibilita aproximar a sociedade da comunidade acadêmica, por meio da adaptação dos resultados das pesquisas respeitando a fidedignidade e o objetivo das mesmas, com o intuito de disseminar e possibilitar aos leigos uma compreensão do que é, como se faz e para que se faz a ciência produzida pelas universidades, centros de pesquisas e afins, visando disseminar o conhecimento científico para comunidade em geral. Além disso inclui no cotidiano das pessoas, em especial nas crianças e adolescentes, conhecimentos como por exemplo, sobre a diversidade de seres vivos que habitam os corpos d'água, e a importância desses organismos para o ecossistema e para a humanidade, possibilitando a sensibilização para conservação da biodiversidade e do respeito ao ambiente (AMORA et al., 2015).

É comum perguntar as pessoas quais organismos vivem na água e elas mencionarem peixes, sapos, cobras, mas raramente mencionam os insetos. Dentre os insetos aquáticos, a ordem Odonata está entre as mais antigas dos insetos alados (DUMONT et al., 2010). Esses insetos são conhecidos popularmente como libélula, jacinta, lava-bunda, lavadeira, cavalo-do-diabo, zig-zag, entre outros (BRASIL et al., 2019). No Brasil a ordem é dividida em duas subordens: Zygoptera e Anisoptera (MIGUEL et al., 2017).

Além de importantes bioindicadores de qualidade de habitat, as libélulas são coloridas e chamam bastante atenção do público em geral por sua beleza (Figura 1) e comportamento, além de ser um representativo símbolo de lendas e culturas em todo o mundo (LENKO et al., 1996), sendo bons modelos para trabalhos de divulgação científica, contribuindo no despertar de uma nova visão dos estudantes e da sociedade sobre a importância dos insetos aquáticos.

Quando praticada no âmbito escolar, a educação ambiental pode atuar como facilitadora no processo de ensino aprendizagem e na construção social de indivíduos conscientes e ecologicamente corretos (FERREIRA, 2013) e quando desenvolvida por meio de projetos, atividades dinâmicas e participativas unindo teoria e prática, exercem o papel de fomentar a criatividade e o raciocínio dos alunos (NARCIZO, 
2012). Assim, a aproximação entre a população e o meio ambiente, utilizando a escola, apresenta-se como uma boa alternativa devido seu papel influenciador sobre a sociedade (BASTOS et al., 2016; SILVA et al., 2020).

A)

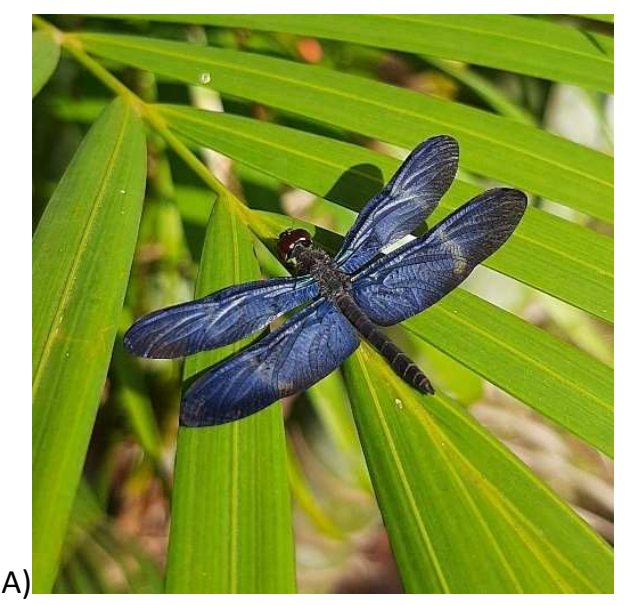

B)

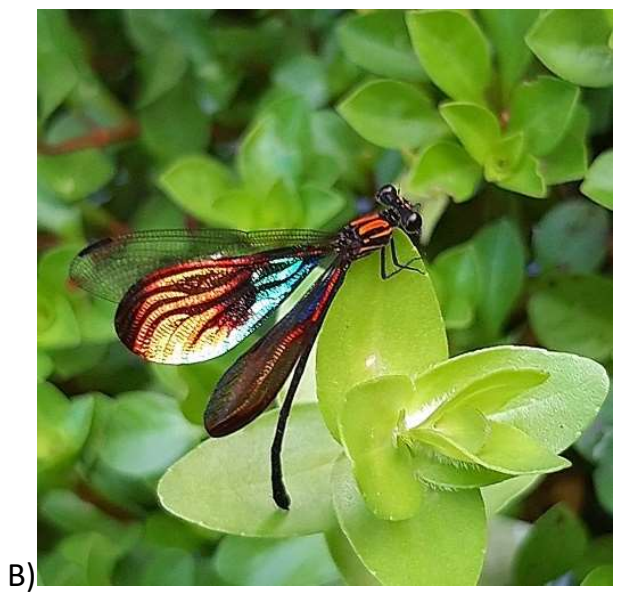

Figura 1: A) Anisoptera- Zenithoptera lanei (Santos, 1941); B) Zygoptera- Chalcopteryx rutilans (Rambur, 1842).

Nestas perspectivas, projetos extensionistas com abordagens de cunho didático voltadas para popularização da ciência e da educação ambiental na escola, principalmente nas públicas, diminuem a carência de práticas em educação científica (SANTOS, 2016) e são importantes para divulgação e ensino, influenciando no desenvolvimento de ações voltadas para conservação e importância dos ecossistemas aquáticos e dos organismos que neles vivem (AMORA et al., 2015; BRASIL et al., 2019).

Assim, o objetivo deste estudo foi desenvolver um trabalho de extensão em uma escola de ensino público acerca da diversidade das libélulas, buscando destacar a importância da preservação dos igarapés e da biodiversidade aquática tendo como aliada a popularização da ciência; abordar elementos relacionados a nomes populares e entretenimentos.

\section{METODOLOGIA}

O estudo é parte integrante do projeto de extensão intitulado: Universidade na Escola, desenvolvido pelo Laboratório de Insetos Aquáticos do Xingu (LEIAX) na Universidade Federal do Pará e realizada em uma escola pública urbana, localizada no interior da Amazônia, no município de Altamira (PA), tratando-se de um estudo descritivo de natureza qualitativa.

Os sujeitos participantes da ação extensionista foram de aproximadamente 100 discentes pertencentes a quatro turmas do $2 \circ$ e $3 \circ$ anos do ensino médio. As atividades desenvolvidas foram: palestras, atividades com os jogos didáticos, exposição de exemplares de libélulas e questionário.

As palestras foram realizadas pela bolsista do projeto abordando as temáticas: o que são as libélulas, modo de vida, aspectos morfológicos, habitat, reprodução, importância ecológica e curiosidades sobre estes organismos.

Os jogos didáticos utilizados na divulgação científica foram planejados e elaborados pela equipe de trabalho do projeto com o objetivo de contribuir com o processo de ensino e aprendizagem dos discentes de forma lúdica e motivadora, além de estimular o desenvolvimento de habilidades de memória, oralidade, 
trabalho em equipe e a construção e aplicação do conhecimento cientifico ministrados nas palestras. Os jogos utilizados foram: jogo da memória, jogo de tabuleiro e quebra-cabeças inspirados em heróis e em representantes de libélulas.

\section{Descrição dos jogos didáticos}

Jogo da memória: É composto por dezesseis cartas, apresentando oito pares, com imagens de diferentes espécies de libélulas, confeccionadas com PVC e adesivo gráfico (Figura 2). O procedimento para jogar consiste na distribuição das cartas sobre uma mesa ou suporte com as imagens viradas para baixo. Alternadamente os jogadores deverão abrir duas cartas. Se elas formarem um par, são retiradas do jogo, em seguida há uma breve explicação sobre a espécie encontrada, caso não formem os pares, as cartas são viradas novamente e podem ser reviradas em outra jogada. Pode ser jogado por dois jogadores ou quatro (formando duplas). O jogo ajuda a desenvolver a percepção cognitiva e a memória dos alunos, além de abordar conhecimentos sobre as espécies de libélulas.

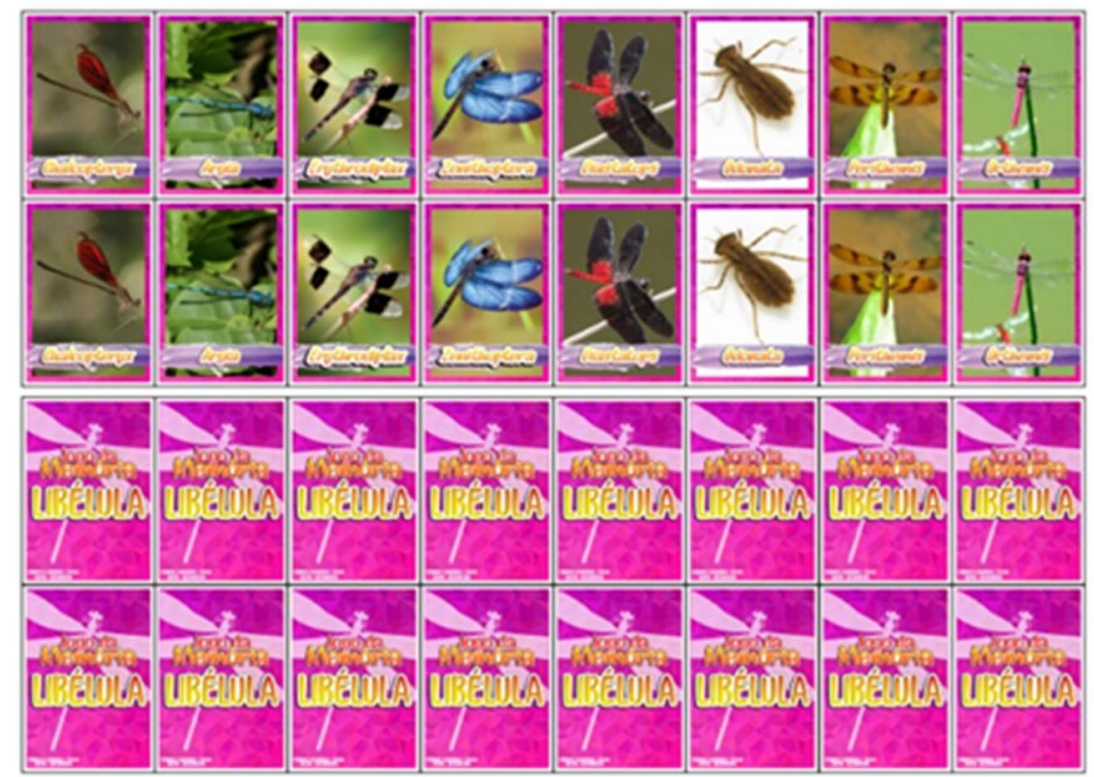

Figura 2: Ilustração das cartas do jogo da memória.

Jogo de tabuleiro "Vida de Libélula": é formado por um tabuleiro que representa o ciclo de vida das libélulas, confeccionado em PVC e adesivo gráfico. É constituído de trinta e seis cartas feitas de papel cartão. As cartas apresentam perguntas de verdadeiro ou falso, respostas faladas e cartas de ação (Figura 3). Assim como os jogos de tabuleiros comuns é preciso realizar um percurso que apresenta um ponto de partida intitulada "ovos" (primeira fase do ciclo de vida dos Odonata) e um ponto de chegada onde termina o jogo, intitulado "Odonata" (representando o fim do ciclo que é a fase adulta).

O aplicador do jogo é responsável por retirar e fazer as leituras das cartas para os jogadores da vez, que irão realizando o trajeto de acordo com a indicação das cartas, e avançando quando responderem de forma correta, quando errarem, permanecem na mesma posição, até o primeiro que realizar todo o trajeto, que será o ganhador. Podem participar quatro jogadores ou oito (formando duplas), após terem passado por uma breve aula sobre as características gerais da ordem em questão. $\mathrm{O}$ jogo proporciona o desenvolvimento 
de habilidades de raciocínio, concentração, aplicação do conhecimento, socialização, desenvolvimento cognitivo e emocional para aceitar as perdas e erros.

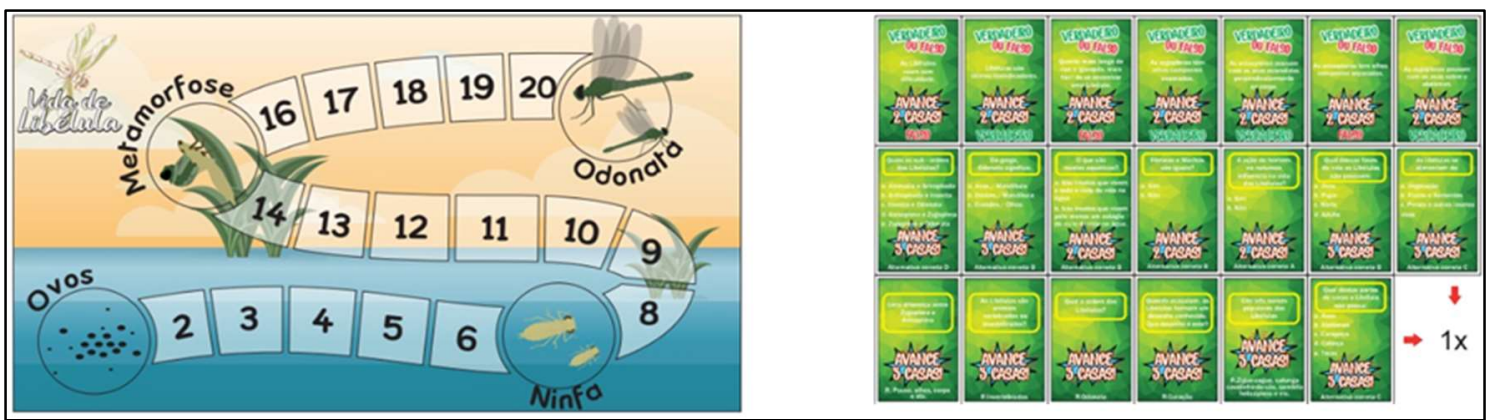

Figura 3: Ilustração do tabuleiro e das cartas do jogo.

Quebra-cabeça: foram confeccionadas seis unidades. Cada unidade contém nove peças. O material utilizando para construção foram: PVC e adesivo gráfico de larva de Odonata. Sendo uma unidade com espécie da subordem Zygoptera, duas unidades da subordem Anisoptera, sendo um representante adulto e uma larva e três unidades de heróis que fazem referências a insetos como: Homem Libélula, Besouro Azul, Homem-Formiga e a Vespa com o intuito de fazer com que os jogadores associem os insetos aos personagens de modo a relacionar os insetos e sua respectiva importância (Figura 4). Se joga como em um quebra-cabeça comum, as peças devem ser encaixadas de modo a completar a imagem. Podem jogar seis pessoas, cada uma com uma unidade, ou em duplas. O jogo auxilia no desenvolvimento de habilidades cognitivas, motoras, visuais e sociais além de fazer referências a heróis fictícios com associações ao cotidiano dos alunos.

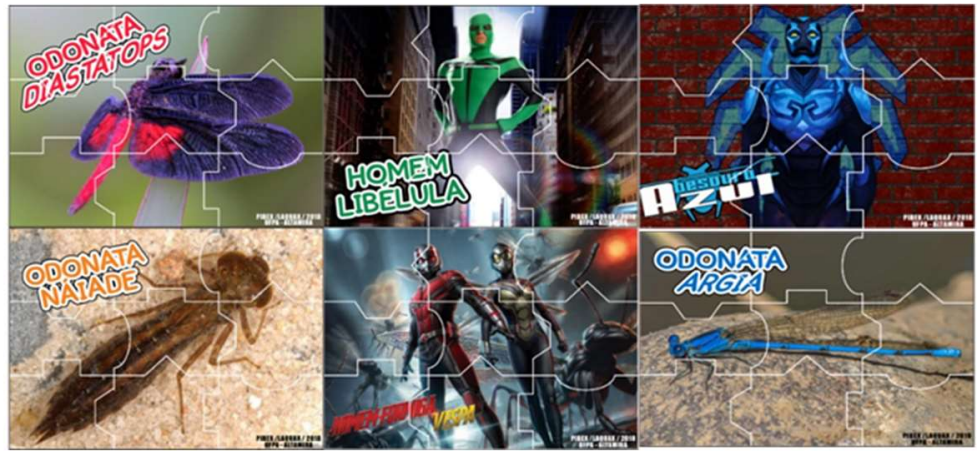

Figura 4: Ilustração dos quebra-cabeças contendo imagens das libélulas e super-heróis.

Houve a exposição de exemplares de libélulas da coleção didática do laboratório, além de abordar questões relacionadas aos estudos e pesquisas, método de coleta e a utilização da licença, destacando a proibição da captura recreativa destes organismos.

Ao término de todas as atividades foi aplicado um questionário com o objetivo de identificar conhecimentos e percepções dos educandos relacionados as libélulas. Dentre eles, destacam-se: a) nomes e designações dadas as libélulas pelos discentes; b) nomes de entretenimentos educativos (filmes ou desenhos) que contém a presença de libélulas.

\section{DISCUSSÃO TEÓRICA}

Em relação as respostas obtidas do questionário diagnóstico tivemos a participação de 75 discentes, 
sendo que as duas perguntas realizadas permitiam mais de uma resposta. Conforme a primeira questão quanto aos nomes e designações dada as libélulas, obtivemos: $38 \%$ dos discentes não responderam à questão. Esse dado nos indica que a temática é pouco conhecida no espaço informal ou abordada no contexto escolar. Os nomes populares mencionados pelos discentes foram: Libelulinha (3\%), Lava bunda (4\%), Zig-zag (11\%), Helicóptero (16\%), Cambito (27\%), segundo o gráfico abaixo (Figura 5). Os nomes citados apenas uma vez não foram representados no gráfico, sendo eles: Donzelinha, Lavadeira, Jacinta, Mariposa e Cigarra.

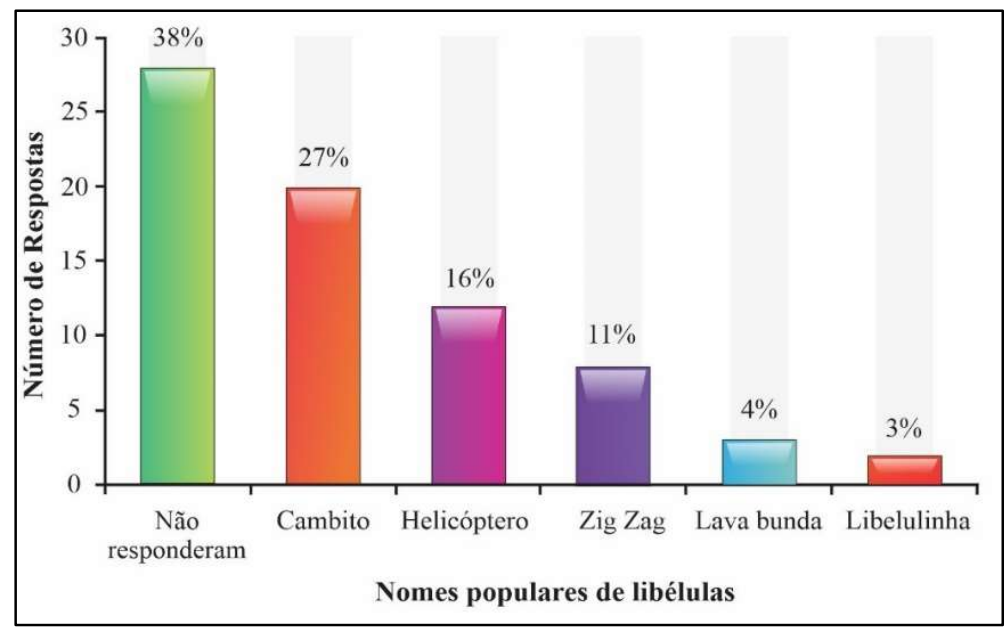

Figura 5: Nomes populares para as libélulas conhecidos pelos discentes do estudo.

Os nomes populares atribuídos as libélulas apresentam uma relação visual de algumas características e comportamentos das libélulas, bem como, com as relações culturais, vivências e crenças passadas de geração em geração pelo senso comum e que apresenta variações nas diferentes regiões (SAPIR, 1980), explicando o fato de as libélulas apresentarem tantos nomes populares diferentes em todo o Brasil.

Podemos citar como exemplos as seguintes designações populares dadas as libélulas: "Cambito", "Libelulinha" e "Donzelinha" são pertencentes a subordem Zygoptera, por serem mais delicadas e menos robustas. Outras designações como "Helicóptero" e "Zig zag" está associado ao voo alto e a forma de pairar no ar, como as representantes da subordem Anisoptera que são mais robustas e mais ativas em relação ao voo (CORBET, 1999). O nome "lava-bunda" e "lavadeira" podem ser nomes associados as libélulas devido ao comportamento de oviposição, onde as libélulas "lavam" a parte final do abdômen com o movimento de bater na superfície dos corpos d'água para depositar seus ovos (HAMADA et al., 2014).

Segundo o dicionário Houaiss et al. (2009) o nome "Jacinta" é um vocábulo regional da Amazônia e a etimologia da palavra é desconhecida. Outros nomes como "mariposa" e "cigarra" podem ser explicados pela associação equivocada de características semelhantes às libélulas como o voo e a presença de asas, o que implica na importância do desenvolvimento de ações extensionistas que proporcionam a quebra desses equívocos, tornando possível a identificação das libélulas na natureza e de suas peculiares características e comportamentos por parte dos discentes.

$\mathrm{Na}$ segunda questão relacionada a mencionar nomes de entretenimentos educativos (filmes ou desenhos) que contém a presença de libélulas, os dados nos apontam os seguintes resultados: $61 \%$ dos discentes não responderam à questão e os entretenimentos mencionados foram: "Homem formiga e a 
vespa”, “A libélula”, “Super Herói” e “Planeta Terra” (3\% cada), Lucas, Um Intruso no Formigueiro” (6\%), Libélula" (10\%), "Homem-Libélula" (13\%), conforme demostrado no gráfico abaixo (Figura 6).

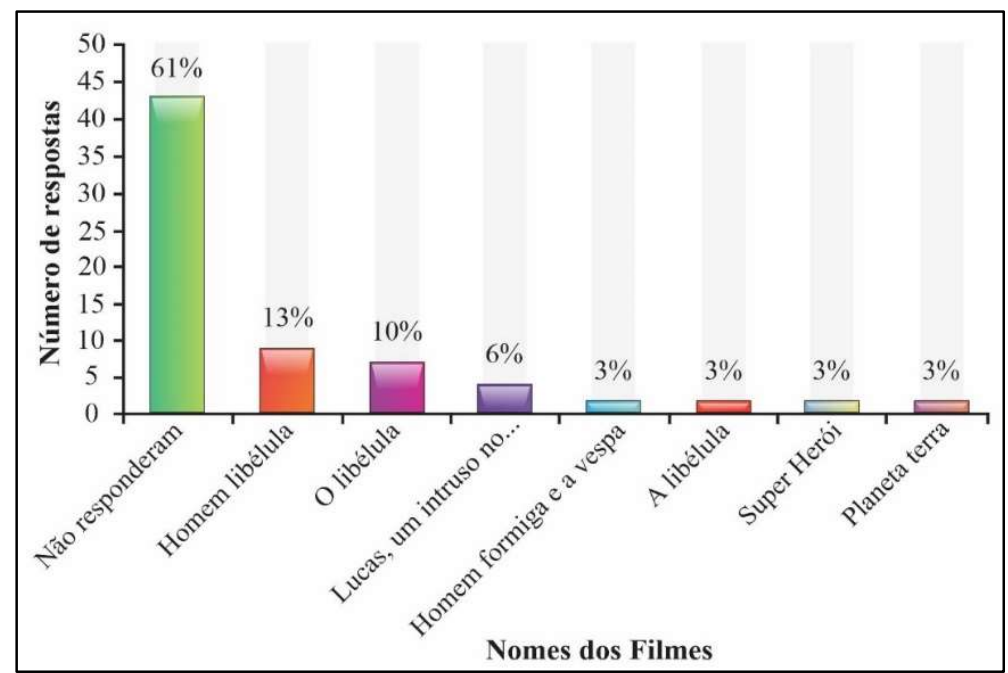

Figura 6: Nomes de filmes que apresentavam libélulas segundo os discentes do estudo.

O filme "Homem-Libélula" e "O Libélula" são o mesmo filme intitulado "Super-Herói, O Filme", este é um filme de comédia o qual o ator principal é um herói atrapalhado chamado "O Libélula", seu uniforme possui o desenho de uma libélula. Assim, o organismo quando sendo retratado como personagem principal, acaba apresentando uma maior notoriedade pelo público.

Em “Lucas, um intruso no Formigueiro" não aparece qualquer libélula, possivelmente tenha sido uma associação errada com vespas ou com a formiga rainha que aparece em uma das cenas principais do filme com a presença de asas. Quanto aos outros filmes ou desenhos citados não foi possível fazer qualquer tipo de relação com as libélulas, o que também pode ser explicado por confundirem as libélulas com outros insetos alados. Tal equívoco exemplifica a deficiência no devido reconhecimento dos insetos e das características que os diferem (COSTA-NETO et al., 2004), demonstrando a necessidade de trabalhos de popularização da entomologia aquática e sua utilização como ferramenta de educação ambiental em escolas.

Durante a realização das atividades os discentes fizeram questionamentos relacionados as dúvidas que tinham acerca das libélulas. Dentre elas podemos mencionar: "por que elas batem a bunda na água?" Referindo-se ao processo de postura de ovos realizado pelas fêmeas na superfície da água (MARTINS et al., 2011), "o que elas fazem enquanto voam juntas?" Tal pergunta faz relação com uma etapa da reprodução chamada de tandem, neste momento o macho segura a fêmea pela junção entre o protórax e a cabeça e os dois voam juntos, o acasalamento também pode ocorrer em pleno voo (PALACINO et al., 2017), "por que ficam se debatendo nas lâmpadas? Este comportamento pode ser gerado pois muitos insetos, como as libélulas são atraídos pela luz da lâmpada (PEREIRA et al., 2009).

Tais questionamentos demostram que alguns discentes apresentam um conhecimento prévio das libélulas e até relataram experiências vividas na infância, mas apesar de conhecerem as libélulas visualmente, não sabiam seu papel quanto organismo no ecossistema e a importância em preservá-las. Muitos não conheciam os insetos aquáticos e ficaram surpresos quando souberam que as libélulas apresentam uma fase 
larval e que nesse período vivem no ambiente aquático. Para Germano et al. (2007) é imprescindível que haja o resgate das experiências e conhecimentos do senso comum para dar visibilidade aos diversos saberes, estabelecendo diálogos em torno de questões simples do cotidiano, buscando orientá-los para uma compreensão científica.

\section{CONCLUSÕES}

Além da troca e compartilhamento de saberes a popularização da ciência por meio das ações extensionistas, tem o papel de auxiliar no ensino da divulgação cientifica (DC), permitindo um diálogo entre a vivência dos participantes e das informações científicas, contribuindo na formação de sujeitos críticos, autônomos e participativos.

Ressalta-se a importância de se associar práticas educativas ao cotidiano do contexto escolar como forma de aliar o conhecimento popular com o conhecimento científico e a utilização da zoologia cultural associada a entretenimentos como jogos, filmes e desenhos podem apresentar-se como uma boa alternativa na construção de uma ligação didática entre cultura e ciência.

Com esta atividade proporcionamos aos discentes conhecimentos específicos de quem são as libélulas, como vivem e qual sua importância ecológica, estimulando nos discentes a sensibilização pela necessidade de preservação dos ambientes aquáticos e consequentemente das espécies de libélulas. Assim, os projetos de extensão como este proporcionam uma maior aproximação da comunidade acadêmica e escolar, efetivando desta forma a popularização da ciência e as ações de educação ambiental.

\section{AGRADECIMENTOS}

À PRÓ-REITÓRIA DE EXTENSÃO (PROEX) pelo financiamento à pesquisa.

\section{REFERÊNCIAS}

ALLAN, J. D.. Landscapes and riverscapes: the influence of land use on stream ecosystems. Annual Review of Ecology, Evolution, and Systematics, v.35, p.257-284, 2004. DOI: https://doi.org/10.1146/annurev.ecolsys.35.120202.110122

AMORA, G.; DIAS-SILVA, K.; HAMADA, N.. Insetos aquáticos como ferramenta para popularizar a Ciência e promover a inclusão social. Revista Brasileira de Zoologia, Curitiba, v.144, p.8-10, 2015.

BASTOS, D. B. D.; RABINOVICl, A.. A importância do processo de formação de educadores ambientais na efetividade do Programa Nacional de Escolas Sustentáveis. Revista Brasileira de Educação Ambiental, São Paulo, v.11, n.4, p.42-59, 2016. DOI:

https://doi.org/10.34024/revbea.2016.v11.2294

BRASIL, L. S.; VILELA, D. S.. Peculiaridades regionais na percepção de brasileiros sobre libélulas: nomenclatura popular e conservação. Hetaerina Boletín de la Sociedad de Odonatología Latinoamericana, v.1, n.1, p.15-20, 2019.

BRIED, J.; RIES, L.; SMITH, B.; PATTEN, M.; ABBOTT, J.; BALLDAMEROW, J.; CANNINGS, R.; CORDERO-RIVERA, A.;
CÓRDOBA-AGUILAR, A.; MARCO, P.; DIJKSTRA, K. D.; DOLNÝ, A.; GRUNSVEN, R. V.; HALSTEAD, D.; HARABIŠ, F.; HASSALL, C.; JEANMOUGIN, M.; JONES, C.; JUEN, L.; KALKMAN, V.; KIETZKA, G.; MAZZACANO, C. S.; ORR, A.; PERRON, M. A.; ROCHA-ORTEGA, M.; SAHLÉN, G.; SAMWAYS, M.; SIEPIELSKI, A.; SIMAIKA, J.; SUHLING, F.; UNDERHILL, L.; WHITE, E.. Towards global volunteer monitoring of odonate abundance. BioScience, v.70, n.10, p.914-923, 2020. DOI: https://doi.org/10.1093/biosci/biaa092

BUENO, W. D. C.. Jornalismo científico no Brasil: aspectos teóricos e práticos. São Paulo: USP, 1988.

CORBET, P. S.. Dragonflies: behaviour and ecology of Odonata. Harley books, 1999.

COSTA NETO, E. M. C.; PACHECO, J. M.. A construção do domínio etnozoológico "inseto" pelos moradores do povoado de Pedra Branca, Santa Terezinha, Estado da Bahia. Acta Scientiarum. Biological Sciences, v.26, n.1, p.81-90, 2004. DOI: https://doi.org/10.4025/actascibiolsci.v26i1.1662

COUCEIRO, S. R. M.; HAMADA, N.; LUZ, S. L. B.; PIMENTEL, T. $P$.. Deforestation and sewage effects on aquatic 
macroinvertebrates in urban streams in Manaus, Amazonas, Brazil. Hydrobiologia, v.575, p.271-284, 2007. DOI: https://doi.org/10.1007/s10750-006-0373-z

DALA-CORTE, R. B.; MELO, A. S.; SIQUEIRA, T.; BINI, L. M.; MARTINS, R. T.; CUNICO, A. M.; PES, A. M.; MAGALHÃES, A. L. B.; GODOY, B. S.; LEAL, C. G.; MONTEIRO-JÚNIOR, C. S.; STENERT, C.; CASTRO, D. M. P.; MACEDO, D. R.; LIMA JUNIOR D. P.; GUBIANI, E. A.; MASSARIOL, F. C.; TERESA, F. B.; BECKER, F. G.; SOUZA, F. N.; VALENTE-NETO, F.; SOUZA, F. L.; SALLES, F. F.; BREJÃO, G. L.; BRITO, J. G.; VITULE, J. R. S.; SIMIÃO-FERREIRA, J.; DIAS-SILVA, K.; ALBUQUERQUE, L.; JUEN, L.; MALTCHIK, L.; CASATTI, L.; MONTAG, L.; RODRIGUES, M. E.; CALLISTO, M. NOGUEIRA, M. A. M.; SANTOS, M. R.; HAMADA, H.; PAMPLIN, P. A. Z.; POMPEU, P. S.; LEITÃO, R. P.; RUARO, R.; MARIANO, R.; COUCEIRO, S. R. M.; ABILHOA, V.; OLIVEIRA, V. C.; SHIMANO, Y.; MORETTO, Y.; SÚAREZ, Y. R.; ROQUE, F. D. O.. Thresholds of freshwater biodiversity in response to riparian vegetation loss in the Neotropical region. Journal of Applied Ecology, v.57, n.7, p.1391-1402, 2020. DOI: https://doi.org/10.1111/13652664.13657

DUMONT, H. J.; VIERSTRAETE, A.; VANFLETEREN, J. R.. A molecular phylogeny of the Odonata (Insecta). Systematic Entomology, v.35, p.6-18, 2010. DOI: https://doi.org/10.1111/j.1365-3113.2009.00489.x

FERREIRA, C. E. A.. O meio ambiente na prática de escolas públicas da rede estadual de São Paulo: intenções e possibilidades. Ambiente \& Educação, São Paulo, v.18, n.1, p.185-209, 2013.

GERMANO, M. G.; KULESZA, W. A.. Popularização da ciência: uma revisão conceitual. Caderno Brasileiro de ensino de Física, v.24, n.1, p.7-25, 2007. DOI:

https://doi.org/10.5007/\%25x

HAMADA, N.; NESSIMIAN, J. L.; QUERINO, R. B.. Insetos aquáticos na Amazônia brasileira: taxonomia, biologia e ecologia. Manaus: INPA, 2014.

HOUAISS, A.; VILLAR, M. D. S.. Dicionário Houaiss da língua portuguesa. Rio de Janeiro: Objetiva, 2009.

JUEN, L.; CUNHA, E. J.; CARVALHO, F. G.; FERRERIA, M. C.; BEGOT, T.O.; ANDRADE, A. L.; SHIMANO, Y.; LEÃO, H.; POMPEU, S. MONTAG, L. F. A.. Effects of oil palm plantations on the habitat structure and biota of streams in Eastern
Amazon. River Research and Applications, v.32, n.10, p.2081-2094, 2016. DOI: https://doi.org/10.1002/rra.3050

LENKO, K.; PAPAVERO, N.. Insetos no folclore. São Paulo: Conselho Estadual de Artes e Ciências Humanas, 1996.

MARTINS, F. A.; DEL CLARO, K.. História natural nas interações entre libélulas (odonata) da vegetação de cerrado. Horizonte Científico, v.5, n.2, p.1-20, 2011.

MATEUS, W.; GONÇALVES, C.. Discutindo a divulgação científica: o discurso e as possibilidades de divulgar ciência na internet. Revista Areté - Revista Amazônica de Ensino de Ciências, v.5, n.9, p.29-43, 2017

MIGUEL, T. B.; OLIVEIRA JUNIOR, J. M. B.; LIGEIRO, R.; JUEN, L.. Odonata (Insecta) as a tool for the biomonitoring of environmental quality. Ecological Indicators, v.81, p.555566, 2017. DOI:

https://doi.org/10.1016/j.ecolind.2017.06.010

NARCIZO, K. R. S.. Uma análise sobre a importância de trabalhar educação ambiental nas escolas. Revista Eletrônica do Mestrado em Educação Ambiental, v.22, p.8694, 2012. DOI: https://doi.org/10.14295/remea.v22i0.2807

PALACINO, F.; BOTA, C.; AMAYA, C.; CONTRERAS, N.. Libélulas y caballitos del diablo del departamento del Meta, Colombia. Universidad del Bosque, 2017.

PEREIRA, A. C. F.; SILVA, H. S.. Levantamento da entomofauna noturna de uma região antropizada no norte de Minas Gerais. In: CONGRESSO DE ECOLOGIA DO BRASIL, 4. Anais. Belo Horizonte: SEB, 2009.

SAPIR, E.. A linguagem: introdução ao estudo da fala. São Paulo: Perspectiva, 1980.

SANTOS, C. A. D.. Divulgação da ciência e educação ambiental através da exposição de insetos aquáticos no museu do instituto biológico. Revista Educação Ambiental em Ação, v.15, n.56, 2016.

SILVA, D. P. P.; MEDEIROS, P. S. M.; CARAMELLO, N. D. A.. Percepção de educadores sobre aspectos da educação ambiental em escolas do município de Ji-Paraná/RO. Revista Ibero Americana de Ciências Ambientais, v.11, n.6, p.1-12, 2020. DOI: https://doi.org/10.6008/CBPC21796858.2020.006.0055

A CBPC - Companhia Brasileira de Produção Científica (CNPJ: 11.221.422/0001-03) detém os direitos materiais desta publicação. Os direitos referem-se à publicação do trabalho em qualquer parte do mundo, incluindo os direitos às renovações, expansões e disseminações da contribuiç̃o, bem como outros direitos subsidiários. Todos os trabalhos publicados eletronicamente poderão posteriormente ser publicados em coletâneas impressas sob coordenação da Sustenere Publishing, da Companhia Brasileira de Produção Científica e seus parceiros autorizados. Os (as) autores (as) preservam os direitos autorais, mas não têm permissão para a publicação da contribuição em outro meio, impresso ou digital, em português ou em tradução. 